\title{
Optimization of ultrasonic-assisted enzymatic hydrolysis conditions for the production of antioxidant hydrolysates from porcine liver by using response surface methodology
}

\author{
Hui-Chuan $\mathrm{Yu}^{1}$ and Fa-Jui $\operatorname{Tan}^{1, *}$
}

\begin{abstract}
* Corresponding Author: Fa-Jui Tan Tel: +886-4-22870613 (246), Fax: +886-4-22860265, E-mail: tanfj@dragon.nchu.edu.tw
\end{abstract}

'Department of Animal Science, National Chung Hsing University, Taichung 402, Taiwan

Submitted Oct 14, 2016; Revised Jan 4, 2017; Accepted Feb 5, 2017
Objective: The objective of this study was to optimize ultrasonic-assisted enzymatic hydrolysis conditions, including enzyme-to-substrate $(E / S)$ ratio, $\mathrm{pH}$, and temperature, for producing porcine liver hydrolysates (PLHs) with the highest 1,1-diphenyl-2-picrylhydrazyl (DPPH) free radical scavenging activity by using response surface methodology (RSM).

Methods: The study used RSM to determine the combination of hydrolysis parameters that maximized the antioxidant activity of our PLHs. Temperature $\left(40^{\circ} \mathrm{C}, 54^{\circ} \mathrm{C}\right.$, and $\left.68^{\circ} \mathrm{C}\right), \mathrm{pH}(8.5$, 9.5 , and 10.5$)$, and $E / S$ ratio $(0.1 \%, 2.1 \%$, and $4.1 \%)$ were selected as the independent variables and analyzed according to the preliminary experiment results, whereas DPPH free radical scavenging activity was selected as the dependent variable.

Results: Analysis of variance showed that $E / S$ ratio, $\mathrm{pH}$, and temperature significantly affected the hydrolysis process $(\mathrm{p}<0.01)$. The optimal conditions for producing PLHs with the highest scavenging activity were as follows: $E / S$ ratio, $1.4 \%(v / w)$; temperature, $55.5^{\circ} \mathrm{C}$; and initial $\mathrm{pH}$, 10.15. Under these conditions, the degree of hydrolysis, DPPH free radical scavenging activity, ferrous ion chelating ability, and reducing power of PLHs were $24.12 \%, 79 \%, 98.18 \%$, and 0.601 absorbance unit, respectively. The molecular weight of most PLHs produced under these optimal conditions was less than 5,400 Da and contained $45.7 \%$ hydrophobic amino acids.

Conclusion: Ultrasonic-assisted enzymatic hydrolysis can be applied to obtain favorable antioxidant hydrolysates from porcine liver with potential applications in food products for preventing lipid oxidation.

Keywords: Antioxidant Activity; Hydrolysate; Liver; Response Surface Methodology; Ultrasound

\section{INTRODUCTION}

Porcine liver, a byproduct of pig slaughtering, contains many nutrients [1]; however, it is rarely consumed probably because of its high cholesterol content [2]. Underutilization of such byproducts leads to potential economic loss and increases disposal cost. Enzymatic hydrolysis is used to recover and improve the nutritional and functional properties of proteins from fish and animal byproducts, such as tuna [3,4], chicken [5], and porcine liver [1], to yield valuable components. Alcalase, an endoproteinase, can hydrolyze proteins to peptides possessing hydrophobic amino acids at the end of their peptide chains. These hydrophobic amino acids increase the affinity between the peptides and fatty acids [6-8], thus attracting the antioxidant amino acid residues toward the radical species and unsaturated fatty acids, finally increasing the antioxidant activities of the hydrolysates $[9,10]$.

Ultrasonication involves the propagation of longitudinal pressure waves, further leading to the cavitation phenomenon. Within the regions undergoing cavitation pressure changes, mechani- 
cal shear forces cause cell damage, resulting in the release of more proteins [11]. Furthermore, during ultrasonication, larger protein molecules break down into smaller particles and protein aggregate structures loosen [12]. These processes improve the efficiency of protein extraction and hydrolysis. Response surface methodology (RSM) has been widely applied to optimize experimental conditions and maximize response within a specified range of factors [13]. Some process parameters, such as type of hydrolyzing enzyme, substrate protein, degree of hydrolysis $(\mathrm{DH})$, substrate pretreatment, and environmental conditions are considered as the key points to a successful hydrolysis [14]. Kristinsson and Rasco [15] indicated that enzyme reaction kinetics was remarkably affected by hydrolysis temperature and $\mathrm{pH}$. The cleavage degree of protein in the substrate could be controlled and the hydrolysates with different molecular profiles and functional properties could be produced by using appropriate enzyme-tosubstrate $(E / S)$ ratios. Guerard et al [16] reported that during hydrolysis of shrimp processing discards, $\mathrm{pH}$ and temperature played critical roles in enhancing antiradical activity. When maintaining the hydrolysis temperature at approximately $52^{\circ} \mathrm{C}$, it might unfold protein, expose the hydrophobic residues buried inside the molecular, facilitate the protein degradation, and eventually increase the antioxidant activity of grass carp sarcoplasmic protein hydrolysates [10]. Plant proteins are generally used as raw materials for ultrasonic-assisted enzymatic hydrolysis $[8,17]$. This study aimed to i) model the effects of $E / S$ ratio, $\mathrm{pH}$, and temperature on the 1,1-diphenyl-2-picrylhydrazyl (DPPH) free radical scavenging activity and $\mathrm{DH}$ of the ultrasonic-assisted enzymatic hydrolysis of porcine liver protein, ii) optimize the reaction to obtain the maximum DPPH free radical scavenging activity by using RSM, and iii) characterize the porcine liver protein hydrolysates (PLHs) obtained under the optimal conditions.

\section{MATERIALS AND METHODS}

\section{Preparation of PLHs}

PLHs were produced according to the methods of Hsu [18] with some modifications. Porcine liver (50 g) was homogenized (NISSEI AM-12, Tokyo, Japan) with $100 \mathrm{~mL}$ of distilled water at 10,000 rpm for $1 \mathrm{~min}$ and heated at $95^{\circ} \mathrm{C}$ to $100^{\circ} \mathrm{C}$ for $5 \mathrm{~min}$ to inactivate indigenous enzymes. The homogenized solution was then equilibrated to a hydrolysis temperature $\left(40^{\circ} \mathrm{C}, 54^{\circ} \mathrm{C}\right.$, and $\left.68^{\circ} \mathrm{C}\right)$ with the $\mathrm{pH}$ was adjusted to $8.5,9.5$, and 10.5 by using $1.0 \mathrm{~N}$ $\mathrm{NaOH}$, after which Alcalase 2.4L (Sigma Chemical Co., St. Louis, MO, USA) was added $(0.1 \%, 2.1 \%$, and $4.1 \%$ of $E / S$ ratio, $v / w)$ and the solution was further hydrolyzed for $30 \mathrm{~min}$ in an ultrasonic cleaner (40 kHz, $400 \mathrm{~W}$; DELTA DC400H, New Taipei City, Taiwan). After the reaction, the mixture was heated at $95^{\circ} \mathrm{C}$ to $100^{\circ} \mathrm{C}$ for $10 \mathrm{~min}$ to inactivate Alcalase and then centrifuged (Himac centrifuge SCR20B, Hitachi, Tokyo, Japan) at 10,000 g for $10 \mathrm{~min}$. The supernatant was filtered through a Whatman No. 1 filter paper to obtain PLHs. After the DH was determined, PLHs were lyophilized and stored at $-20^{\circ} \mathrm{C}$ until further analysis.

\section{Response surface methodology}

We used RSM to determine the combination of hydrolysis parameters that maximized the antioxidant activity of our PLHs. Temperature, $\mathrm{pH}$, and $E / S$ ratio were selected as the independent variables and analyzed according to the preliminary experiment results, whereas DPPH free radical scavenging activity was selected as the dependent variable. A Box-Behnken design comprising 15 experiments was used. The experiment design and dependent variable values are presented in Table 1.

Regression analysis was performed for the experiment data and fitted into the following second-order polynomial model:

$$
\begin{aligned}
Y= & \beta_{0}+\beta_{1} X_{1}+\beta_{2} X_{2}+\beta_{3} X_{3}+\beta_{11} X_{1}^{2}+\beta_{22} X_{2}^{2} \\
& +\beta_{33} X_{3}^{2}+\beta_{12} X_{1} X_{2}+\beta_{13} X_{1} X_{3}+\beta_{23} X_{2} X_{3}
\end{aligned}
$$

Where $Y$ is the dependent variable (i.e., DPPH free radical scavenging activity); $X_{1}, X_{2}$, and $X_{3}$ are independent variables [19]; $\beta_{0}$ is a constant term; $\beta_{1}, \beta_{2}$, and $\beta_{3}$ are the linear, quadratic, and cross-product regression coefficients. The analysis of experimental design, calculation of predicted data, and plotting of surface plot were conducted using Minitab 16 (Minitab Inc., State College, PA, USA).

\section{Degree of hydrolysis measurement}

The DHs of PLHs were determined by measuring the increase in free amino groups by using a picrylsulfonic acid solution according to the method of Adler-Nissen [20] and calculated as follows:

Table 1. Box-Behnken design matrix and responses of dependent variables for

\begin{tabular}{|c|c|c|c|c|c|}
\hline \multirow[b]{2}{*}{ Experiment } & \multicolumn{3}{|c|}{ Independent variables } & \multicolumn{2}{|c|}{ Responses } \\
\hline & $\begin{array}{c}E / S(\%, v / w) \\
\left(X_{1}\right)\end{array}$ & $\begin{array}{c}\mathrm{pH} \\
\left(X_{2}\right)\end{array}$ & $\begin{array}{c}\mathrm{T}\left({ }^{\circ} \mathrm{C}\right) \\
\left(X_{3}\right)\end{array}$ & $\mathrm{DH} \%$ & $\begin{array}{l}\text { DPPH radical } \\
\text { scavenging } \\
\text { activity (\%) (Y) }\end{array}$ \\
\hline 1 & 0.1 & 8.5 & 54 & 16.91 & 73.24 \\
\hline 2 & 4.1 & 8.5 & 54 & 25.46 & 67.62 \\
\hline 3 & 0.1 & 10.5 & 54 & 20.96 & 78.34 \\
\hline 4 & 4.1 & 10.5 & 54 & 26.11 & 77.02 \\
\hline 5 & 0.1 & 9.5 & 40 & 20.23 & 75.87 \\
\hline 6 & 4.1 & 9.5 & 40 & 25.30 & 67.16 \\
\hline 7 & 0.1 & 9.5 & 68 & 21.66 & 76.35 \\
\hline 8 & 4.1 & 9.5 & 68 & 26.79 & 73.03 \\
\hline 9 & 2.1 & 8.5 & 40 & 24.53 & 66.29 \\
\hline 10 & 2.1 & 10.5 & 40 & 24.58 & 75.83 \\
\hline 11 & 2.1 & 8.5 & 68 & 26.32 & 70.68 \\
\hline 12 & 2.1 & 10.5 & 68 & 26.87 & 77.96 \\
\hline 13 & 2.1 & 9.5 & 54 & 24.73 & 79.70 \\
\hline 14 & 2.1 & 9.5 & 54 & 25.81 & 79.23 \\
\hline 15 & 2.1 & 9.5 & 54 & 23.84 & 77.96 \\
\hline
\end{tabular}
antioxidant hydrolysate produced from porcine liver protein

$E / S$, enzyme/substrate; T, temperature; DH, degree of hydrolysis; DPPH, 1,1-diphenyl-2-picrylhydrazyl. 
$\% \mathrm{DH}=\left(h / h_{\text {tot }}\right) \times 100$

Where $h_{\text {tot }}$ is the total number of peptide bonds per protein equivalent, and $h$ is the number of hydrolyzed bonds. The $h_{t o t}$ factor is dependent on raw material amino acid composition.

\section{Antioxidant activity measurement}

The ferrous ion chelating ability of PLHs was determined using the method of Dinis et al [21] and calculated as follows:

Ferrous ion chelating ability (\%)

$$
\begin{aligned}
= & \left(1-\text { absorbance }_{\text {sample }} \text { at } 562 \mathrm{~nm} / \text { absorbance }_{\text {control }} \text { at } 562 \mathrm{~nm}\right) \\
& \times 100
\end{aligned}
$$

The reducing power was determined according to the method of Oyaizu [22] at a wavelength of $700 \mathrm{~nm}$ through spectrophotometry. The DPPH radical scavenging activity was determined using a modified method of Shimada et al [23]. The absorbance of the sample solution was determined as follows:

$\mathrm{DPPH}$ radical scavenging activity (\%)

$$
\begin{aligned}
= & \left(1-\text { absorbance }_{\text {sample }} \text { at } 517 \mathrm{~nm} / \text { absorbance }_{\text {control }} \text { at } 517 \mathrm{~nm}\right) \\
& \times 100
\end{aligned}
$$

\section{Determination of PLH molecular weight distribution and} amino acid composition

The molecular weight distribution of PLHs was determined according to the methods of Aspmo et al [24] with some modifications. Samples $(1 \mu \mathrm{L})$ were analyzed using matrix-assisted laser desorption ionization-time-of-flight mass spectrometry (MALDI-TOF MS; Voyager DE-PRO, Applied Biosystems, NY,
USA) in a positive ion mode, whereas the results were obtained in the linear mode. The amino acid composition of the freezedried PLHs was determined using a modified method of You and $\mathrm{Wu}$ [25]. Briefly, $0.1 \mathrm{~g}$ of PLHs was hydrolyzed with $3 \mathrm{~mL}$ of $4 \mathrm{M}$ methanesulfonic acid, containing 0.2\% 3-(2-aminoethyl) indole under vacuum at $115^{\circ} \mathrm{C}$ for $48 \mathrm{~h}$. The total amino acids were analyzed using an Agilent 1100 series high performance liquid chromatography system (Agilent 1100 Series HPLC Value System, Agilent Technologies, Santa Clara, CA, USA) equipped with ZORBAX Eclipse-AAA column $(4.6 \times 150 \mathrm{~mm}, 3.5 \mu \mathrm{m})$.

\section{Statistical analysis}

The optimization experiments were conducted using RSM with the experimental design model of Minitab 16. The software generated equations describing the behavior of the hydrolysis conditions and antioxidant activities and their coefficient of determination $\left(R^{2}\right)$. Significance was determined at a $95 \%$ probability level.

\section{RESULTS AND DISCUSSION}

\section{Optimization of the hydrolysis process}

$E / S$ ratio, $\mathrm{pH}$, and temperature are the crucial parameters affecting enzyme efficiency during protein hydrolysis $[13,16,19]$. Here, the ranges of optimal $E / S$ ratio, $\mathrm{pH}$, and temperature were $0.1 \%$ to $4.1 \%, 8.5$ to 10.5 , and $40^{\circ} \mathrm{C}$ to $68^{\circ} \mathrm{C}$, respectively (Table 1 ). The resulting DPPH radical scavenging activities and $\mathrm{DH}$ values were $66.3 \%$ to $79.7 \%$, and $16.9 \%$ to $26.9 \%$, respectively.

A response surface model was plotted; the regression coefficients for the linear regression, quadratic regression, and interaction of the three variables $\left(X_{1}, X_{2}\right.$, and $\left.X_{3}\right)$ on the response values $(Y)$ are presented in Table 2. All three independent variables,

Table 2. Estimate-coded regression coefficients for 1,1-diphenyl-2-picrylhydrazyl radical scavenging activity of porcine liver protein hydrolysates

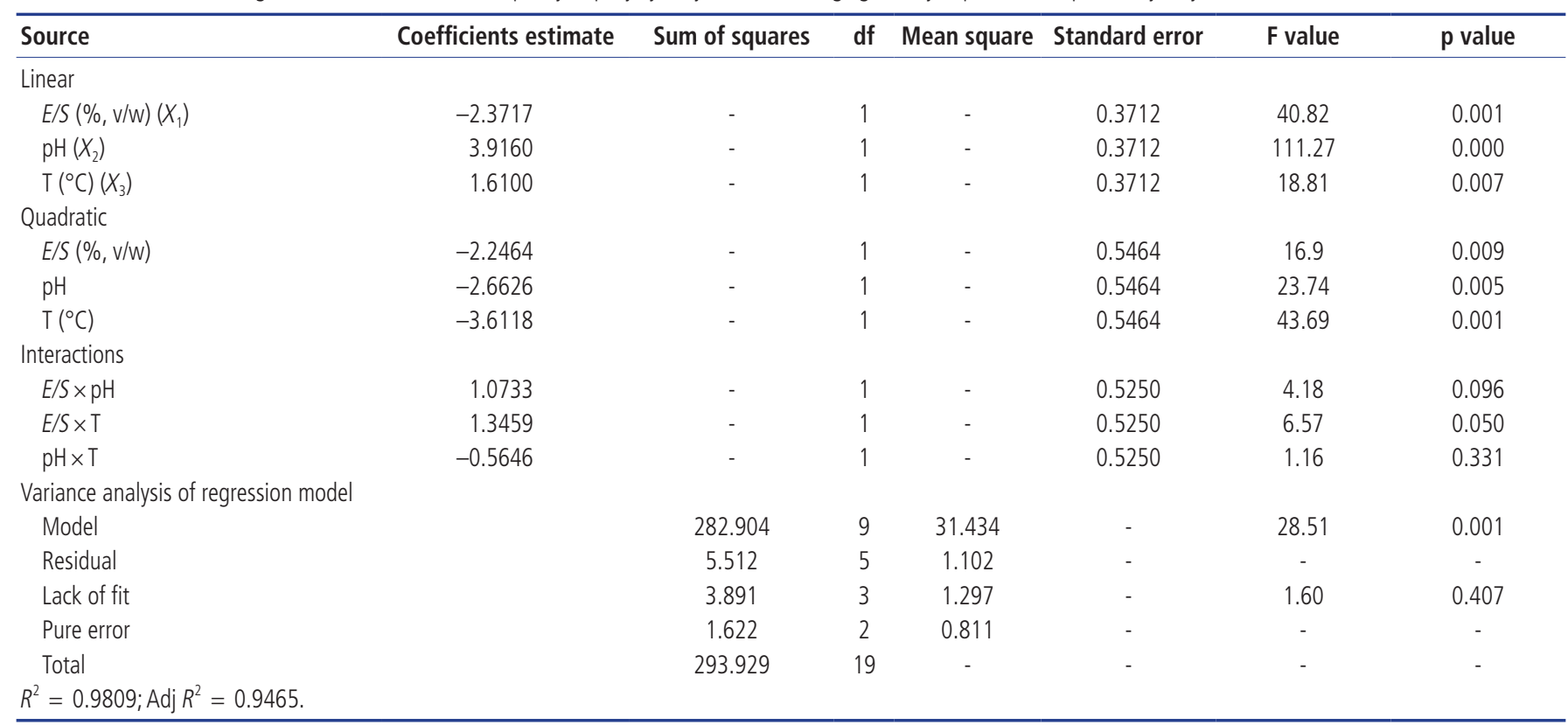

E/S, enzyme/substrate; T, temperature. 
$\mathrm{E} / \mathrm{S}$ ratio, $\mathrm{pH}$, and temperature, demonstrated the highest significant effect on the DPPH radical scavenging activity within a $99 \%$ confidence interval $\left(\mathrm{p}=0.001,0.000\right.$, and 0.007 for $X_{1}, X_{2}$, and $X_{3}$, respectively). All quadratic terms $X_{1} X_{1}(\mathrm{p}<0.009), X_{2} X_{2}$ $(\mathrm{p}<0.005)$, and $X_{3} X_{3}(\mathrm{p}<0.001)$ as well as the interaction term $X_{1} X_{3}(\mathrm{p}=0.05)$ were significant. The results indicated the quadratic items and interactions have great effects on the dependent valuables. Comparison of the monomial coefficient of the regression equation provided the following list of relevant factors in the order of the influence on the DPPH free radical scavenging activity of PLHs: $X_{2}$ (initial $\left.\mathrm{pH}\right)>X_{1}(E / S$ ratio $)>X_{3}$ (temperature). By using RSM, Fang et al [26] indicated that $E / S$ ratio and hydrolysis temperature and time significantly influenced the DPPH radical scavenging activity of hydrolysates derived from flying squid muscle protein. Yu et al [8] reported that the initial $\mathrm{pH}$, ultrasonic power, and reaction temperature significantly influenced the DPPH free radical scavenging activity of peanut hydrolysates.

All terms with statistical significances below $5 \%$ probability level were eliminated (Table 2), providing a simplified model:

$$
\begin{aligned}
Y= & 78.96-2.37 X_{1}+3.92 X_{2}+1.61 X_{3} \\
& -2.25 X_{1}^{2}-2.66 X_{2}^{2}-3.61 X_{3}^{2}+1.35 X_{1} X_{3}
\end{aligned}
$$

Because the values of the linear coefficients for $E / S$ ratio $\left(X_{1}\right)$ were negative, a decrease in $X_{1}$ increased the value of $Y$ (i.e., DPPH radical scavenging activity). The variance analysis of the model given in Table 2 shows that the p value for the model was 0.001 , indicating that the model can adequately monitor the optimization [10]. The $R^{2}$ value (0.9809) was close to 1 , and the adjusted $R^{2}$ value was 0.9465 , indicating that the model explained $94.65 \%$ of the variation in the data and that the experiment error was small; both the $R^{2}$ values were highly significantly, indicating represented the actual relationships between the reaction parameters [10]. The lack-of-fit value of 0.407 indicated that the lackof-fit is nonsignificantly associated with the pure error, illustrating that the selected model was adequate at a $95 \%$ confidence level to describe the observed data [26].

\section{Visual analysis of the RSM experiment}

In this study, the effect of each pair of independent variables on the DPPH free radical scavenging activity of PLHs was shown using contour plots. Figure 1a indicates that with the temperature fixed at $54^{\circ} \mathrm{C}$, the maximum scavenging activity was more than $80 \%$ when the $E / S$ ratio was $0.2 \%$ to $2.5 \%$ and that the $\mathrm{pH}$ was above approximately 9.7. When the $\mathrm{pH}$ was fixed at 9.5, the maximum scavenging activity was obtained at a temperature of $46^{\circ} \mathrm{C}$ to $65^{\circ} \mathrm{C}$ and the $E / S$ ratio of less than $2.8 \%$ (Figure $1 \mathrm{~b}$ ). Finally, at a fixed $E / S$ ratio of $2.1 \%$, the maximum scavenging activity was observed at a temperature of $52^{\circ} \mathrm{C}$ to $62^{\circ} \mathrm{C}$ and a $\mathrm{pH}$ of more than 9.8 (Figure 1c). The antioxidant activity was the highest at high $\mathrm{pH}$, low $E / S$ ratio, and moderate temperature. Chabeaud et al [19] reported that appropriate hydrolysis temperature and $\mathrm{pH}$ enhance the production of antioxidant peptides, subsequently increasing the antioxidant activity of the hydrolysates. During hydrolysis, Sarmadi and Ismail [7] clarified that proteolysis unfolds protein chains, thus exposing more active amino acid $\mathrm{R}$ groups and increasing the antioxidant activity.

The effects of reaction temperature on the antioxidant activity have been well-documented. Generally, the reaction rates increase with temperature, particularly in the approximate range of $40^{\circ} \mathrm{C}$ to $60^{\circ} \mathrm{C}$ (observed in the current study); this is consistent with a study by Kamau and $\mathrm{Lu}$ [14], who indicated that more hydrolyzed products are produced during the hydrolysis. However, when the temperature surpasses a certain level, $\left(68^{\circ} \mathrm{C}\right.$ in this study), the denatured enzymes and substrates may counteract its antioxidant activity because of the excessively high temperatures [8]. As biological catalysts, catalytic activities of proteases are intensively affected by $\mathrm{pH}$. Kamau and $\mathrm{Lu}$ [14] reported that changes in $\mathrm{pH}$ may affect the charge distribution and conformation of the molecules, possibly disturbing the ionic character of the substrate and denaturing the protein structures of the enzyme, thus affecting the binding ability between the substrate and enzyme. Yu et al [8] clarified that more active sites became exposed in a certain $\mathrm{pH}$ range after the spatial structures of protease changed. Some antioxidant hydrolysates are generated
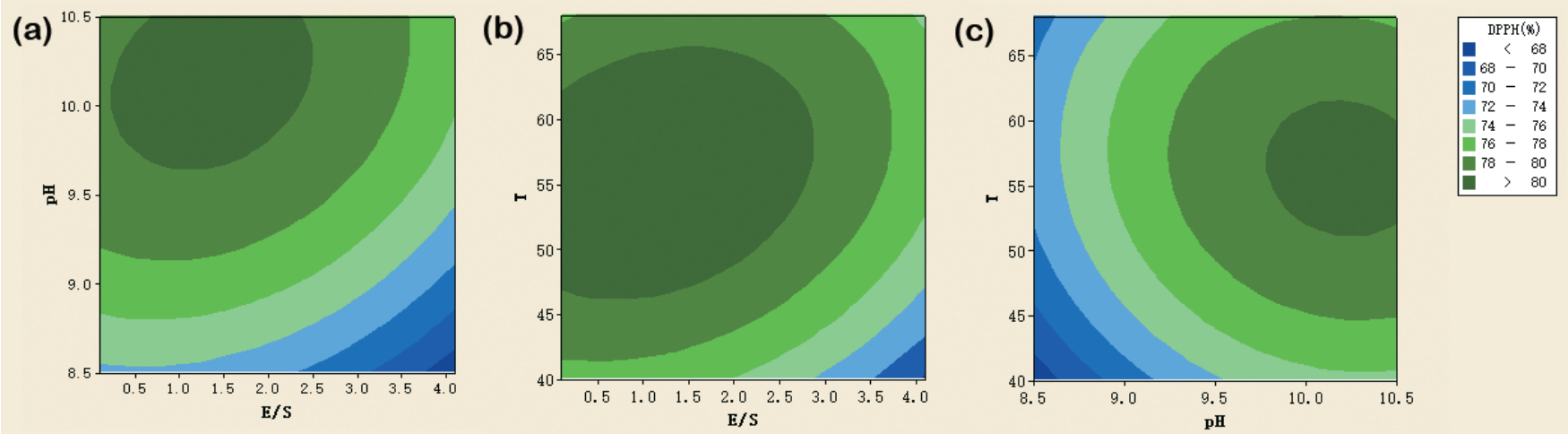

Figure 1. Contour plots of 1,1-diphenyl-2-picrylhydrazyl radical scavenging activity as functions of (a) enzyme-to-substrate (E/S) ratio vs $\mathrm{pH}$ at temperature of $54^{\circ} \mathrm{C}$, (b) $\mathrm{E} / \mathrm{S}$ ratio vs temperature at $\mathrm{pH}$ of 9.5 , and (c) $\mathrm{pH}$ vs temperature at an $\mathrm{E} / \mathrm{S}$ ratio of $2.1 \%$. 
when the peptide bonds in the substrate protein are broken, thus increasing the DPPH free radical scavenging activity. However, as the temperature deviates from the optimal range, the protease denatures, which reduces its scavenging activity. Figure 1c indicated that the optimal $\mathrm{pH}$ for Alcalase activity was approximately 9.7 to 10.5 , corroborating the results of previous studies [16]. When the substrate mass fraction was maintained constant and enzyme dosage was low, several substrate molecules bound to the protease active sites and formed inactive intermediate products; therefore, the antioxidant activity either remained constant or increased gradually with enzyme dosage [8]. As the enzyme concentration increased, proteases bound to more substrate molecules, liberating more antioxidant peptides and increasing antioxidant activities. However, when the enzyme dosage increased to some extent, the excessive hydrolysis probably reduced the probability of contact between the protease and substrate molecules, finally reducing the antioxidant activity of the hydrolysates [27].

In this study, we observed that even at lower $E / S$ ratios, such as $0.1 \%$ (Table 1 ) and less than $0.5 \%$ (Figure 1a, $1 \mathrm{~b}$ ); the hydrolysates showed favorable DPPH free radical scavenging activities. Yu et al [8] reported that during ultrasonic-assisted enzymatic hydrolysis, some bubbles produced through cavitation burst instantaneously, causing extensive mechanical shearing action to loosen substrate protein structures and benefit the enzymatic reaction. In this study, Alcalase easily attacked the inner protein regions, particularly the protein structures that loosened and were degraded because of ultrasonication; this resulted in the release of the hydrophobic amino acids and eventually increased the antioxidant activity [28]. As shown in Figure 1a, even at a lower $E / S$ ratio (i.e., $<0.5 \%$ ) and $\mathrm{pH}$ of approximately 9.7 to 10.5 , the PLH showed high antioxidant activity. Guerard et al [16] reported that at a high $\mathrm{pH}$ of 9.7, chemical hydrolysis may contribute to the hydrolysis process even without adding Alcalase. This may also clarify the high antioxidant activities at higher $\mathrm{pH}$ values and lower $E / S$ ratios observed in the current study.

\section{Optimization of technical conditions}

Here, the following optimal conditions for ultrasonic-assisted enzymatic hydrolysis for the preparation of PLHs were determined using a typical analysis of an experimental model: $E / S$ ratio $\left(X_{1}\right), 1.4333 \%$; initial $\mathrm{pH}\left(X_{2}\right), 10.1566$; and reaction temperature $\left(X_{3}\right), 55.6^{\circ} \mathrm{C}$; the resulting DPPH free radical scavenging activity was predicted to be $80.73 \%$. To confirm the validity of the predicted model, a verification test was performed using the modified process parameters including $E / S$ ratio $\left(X_{1}\right)$ of $1.4 \%$, initial pH $\left(X_{2}\right)$ of 10.15 , and reaction temperature $\left(X_{3}\right)$ of $55.5^{\circ} \mathrm{C}$ under practical considerations. The verification test results illustrated a scavenging activity of $79 \%$, close to the predicted value $(80.73 \%)$; the results confirmed the appropriateness of the model for estimating experimental values.

\section{Degree of hydrolysis and antioxidant activity}

In the present study, the DH, DPPH radical scavenging activity, reducing power, and ferrous ion chelating ability of PLHs produced under the optimal conditions were $24.12 \%, 79 \%, 0.601$ absorbance unit, and $98.18 \%$, respectively. Yu et al [8] and Fang et al [26] reported that hydrolysates obtained from Alcalase exhibited superior antioxidant activities (such as DPPH free radical scavenging activity, reduction capacity and metal ion chelation). Some free metal ions (e.g., $\mathrm{Fe}^{2+}, \mathrm{Cu}^{+}$) can catalyze $\mathrm{H}_{2} \mathrm{O}_{2}$ to hydroxyl radical in the Fenton reaction. Our PLHs could probably donate hydrogen atoms and bind ferrous ions, thus reduced ferrous ion concentrations and accelerated the $\mathrm{H}_{2} \mathrm{O}_{2}$ to $\mathrm{H}_{2} \mathrm{O}$ conversion, and eventually enhanced antioxidant functions [8].

The dispersion of the points for the graphical representation of the relationship between the DPPH scavenging activity and $\mathrm{DH}$ can be noted in Figure 2. The results demonstrated that the scavenging activities of PLHs fluctuated with the changes in the $\mathrm{DH}$ values. No certain pattern or relationship was observed between the two variables in the current study, which corroborates the results of Wu et al [29] and Chabeaud et al [19], who reported

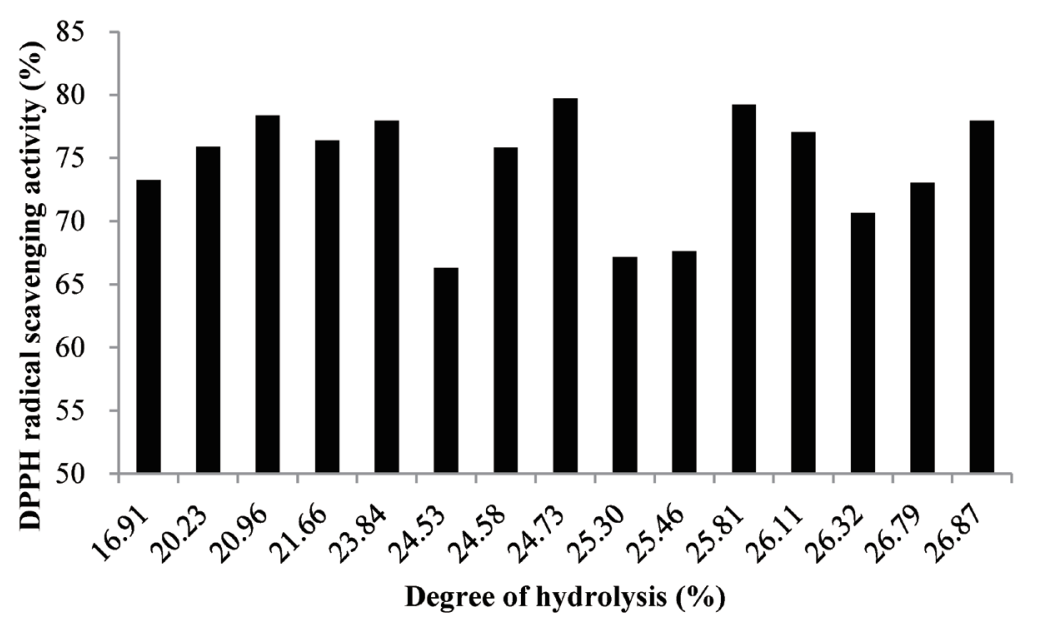

Figure 2. Relationship between 1,1-diphenyl-2-picrylhydrazyl (DPPH) radical scavenging activity and degree of hydrolysis (DH) of porcine liver protein hydrolysates. 
that $\mathrm{DH}$ did not appear to be the major criterion in the production of hydrolysate with antioxidant properties. $\mathrm{DH}$, defined as the percentage of peptide bonds cleaved by protease, has been frequently applied as the index of DH [19,20]. During the increased protein hydrolysis, many low molecular weight peptides and free amino acids with a concomitant increase in the numbers of ionizable groups ( $\mathrm{NH}^{3+}$ and $\mathrm{COO}-$ ) were generated. In the meanwhile, a variation of the molecular structure caused the buried hydrophobic interior to be exposed. The properties of peptides such as molecular structure and size, net charge, and hydrophobicity were also altered [15]. It might enhance the antioxidant activity of hydrolysates. However, during the enzymatic hydrolysis, antioxidant peptides could be formed and degraded continuously. It was primarily influenced by hydrolysis conditions and further changed their molecular structure and sequence. Therefore, the DPPH scavenging activity exhibited alternating increases and decreases during the process of hydrolysis [19]. Hydrolyzed proteins with lower molecular weights (i.e., $<5 \mathrm{kDa}$ ) have been shown to display high antioxidant activities $[9,10]$. In theory, hydrolysates with high DH containing more low-molecular-weight peptides may have higher antioxidant properties. However, Hsu [18] observed that peptides with low molecular weight (i.e., 390 to 1,400 Da) exhibited higher antioxidant activity than did those with a molecular weight of $<390 \mathrm{Da}$, probably because some antioxidant peptides may lose their functional properties after extensive hydrolysis.

Many factors, such as operational conditions, protease type, $\mathrm{DH}$, specific hydrolysate amino acid sequence, peptide struc- ture, and peptide concentration, affect the antioxidant activity of hydrolysates. Therefore, Sarmadi and Ismail [7] reported that the overall antioxidant activity of hydrolysates should be ascribed to the integrative effects of these factors rather than to the individual actions of peptides or amino acids; moreover, the authors indicated that enzyme specificity affects the amount and composition of free amino acid and peptides as well as their amino acid sequence, subsequently influencing the molecular size, hydrophobicity, and antioxidant activity of the hydrolysates.

\section{Molecular weight and amino acid composition of the PLH} produced under optimal conditions

The molecular weight distribution of PLHs was determined through matrix-assisted laser desorption ionization-time-offlight mass spectrometry (MALDI-TOF MS). According to the spectrum shown in Figure 3, most of the molecular weight distribution of the PLHs produced under the optimal conditions was less than 5,400 Da, with several antioxidant properties similar to those of other hydrolysates with a molecular weight less than $5,000 \mathrm{Da}[9,27,29]$.

Table 3 lists that the percentages of the hydrophobic amino acids and aromatic amino acids in the PLHs produced under optimal conditions $-47.50 \%$ and $10.88 \%$, respectively. Hydrophobic amino acids (i.e., Gly, Ala, Val, Trp, Phe, Ile, Leu, Pro, and Met) improve the solubility of the peptides in lipids, thus promoting the peptides better interaction with hydrophobic radical species and hydrophobic polyunsaturated fatty acids [30]. By contrast, aromatic amino acids can donate protons to electron

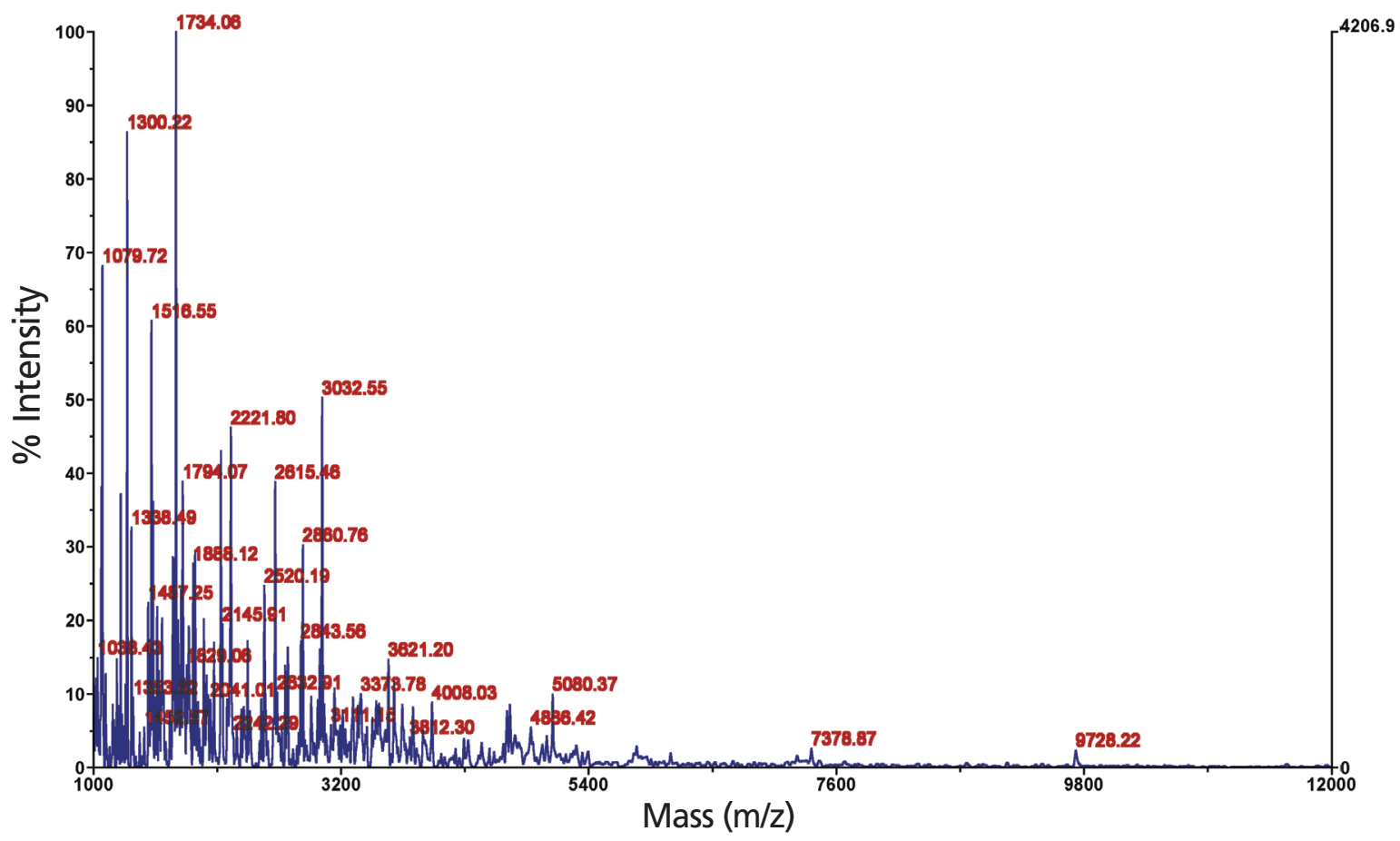

Figure 3. Molecular weight distribution of porcine liver protein hydrolysates produced under the optimal conditions assessed through matrix-assisted laser desorption ionizationtime-of-flight mass spectrometry. 
Table 3. Amino acid compositions of porcine liver protein hydrolysates produced under the optimal conditions

\begin{tabular}{lc}
\hline Amino acid & Content $(\mathbf{g} / \mathbf{1 0 0} \mathbf{g}$ of PLH) \\
\hline Asp & 5.97 \\
Glu & 8.12 \\
Cys & 1.05 \\
Ser & 2.05 \\
His & 1.56 \\
Gly & 3.59 \\
Thr & 2.20 \\
Arg & 2.36 \\
Ala & 4.01 \\
Tyr & 1.34 \\
Val & 3.96 \\
Met & 1.31 \\
Trp & 0.42 \\
Phe & 2.78 \\
lle & 2.78 \\
Leu & 5.50 \\
Lys & 4.78 \\
Pro & 2.30 \\
TAA & 56.1 \\
THAA ${ }^{1 /} /$ TAA $\%$ & 47.50 \\
TAAA ${ }^{2} /$ TAA\% & 10.88 \\
\hline
\end{tabular}

PLH, porcine liver hydrolysate; TAA, total amino acids; THAA, total hydrophobic amino acids; TAAA, total aroma amino acids.

1) Gly, Ala, Val, Trp, Phe, lle, Leu, Pro, and Met.

${ }^{2)}$ Tyr, His, Trp, and Phe.

deficient radicals, stabilizing them; moreover, they can maintain the molecular stability through a resonance structure and then enhance the radical scavenging properties of the amino acids residues [7]. Another contributor to the increased antioxidant properties of the PLHs could be the high content of Asp (10.65\%), considered a metal ion chelator and a hydrogen donor because it has carboxyl and amino groups in the side chain [7].

\section{CONCLUSION}

The DPPH free radical scavenging activity of our PLHs reached $79 \%$ under the optimal conditions, which were as follows: $E / S$ ratio, $1.4 \%$; reaction temperature, $55.5^{\circ} \mathrm{C}$; and initial $\mathrm{pH}, 10.15$. The PLHs showed the highest antioxidant activities and $\mathrm{DH}$ and high content of essential amino acids and hydrophobic amino acids. The MALDI-TOF MS spectra showed that the molecular weight of most hydrolysates was less than 5,400 Da. In conclusion, ultrasonic-assisted enzymatic hydrolysis can be applied to obtain favorable antioxidant hydrolysates from porcine liver with potential applications in food products for preventing lipid oxidation.

\section{CONFLICT OF INTEREST}

We certify that there is no conflict of interest with any financial organization regarding the material discussed in the manuscript.

\section{REFERENCES}

1.Shimizu M, Tanabe S, Morimatsu F, et al. Consumption of pork-liver protein hydrolysate reduces body fat in otsuka long-evanstokushima fatty rats by suppressing hepatic lipogenesis. Biosci Biotech Bioch 2006;70:112-8.

2.Ockerman HW, Basu L. By-products/edible, for human consumption. In: Jensen WK, editor. Encyclopedia of meat sciences. Amsterdam, Netherlands: Elsevier Ltd; 2004. p. 104-12.

3.Je YJ, Lee KH, Lee MH, Ahn CB. Antioxidant and antihypertensive protein hydrolysates produced from tuna liver by enzymatic hydrolysis. Food Res Int 2009;42:1266-72.

4.Ahn CB, Lee KH, Je JY. Enzymatic production of bioactive protein hydrolysates from tuna liver: effects of enzymes and molecular weight on bioactivity. Int J Food Sci Technol 2010;45:562-8.

5. Yang KT, Lin C, Liu CW, Chen YC. Effects of chicken-liver hydrolysates on lipid metabolism in a high-fat diet. Food Chem 2014;160:148-56.

6.Mendis E, Rajapakse N, Byun HG, Kim SK. Investigation of jumbo squid (Dosidicus gigas) skin gelatin peptides for their in vitro antioxidant effects. Life Sci 2005;77:2166-78.

7.Sarmadi BH, Ismail A. Antioxidative peptides from food proteins. A review. Peptides 2010;31:1949-56.

8.Yu L, Sun J, Liu S, et al. Ultrasonic-assisted enzymolysis to improve the antioxidant activities of peanut (Arachin conarachin L.) antioxidant hydrolysate. Int J Mol Sci 2012;13:9051-68.

9.Dong S, Zeng M, Wang D, et al. Antioxidant and biochemical properties of protein hydrolysates prepared from Silver carp (Hypophthalmichthys molitrix). Food Chem 2008;107:1485-93.

10. Ren J, Zhao M, Shi J, et al. Optimization of antioxidant peptide production from grass carp sarcoplasmic protein using response surface methodology. LWT-Food Sci Technol 2008;41:1624-32.

11. Iida Y, Tuziuti T, Yasui K, Kozuka T, Towata A. Protein release from yeast cells as an evaluation method of physical effects in ultrasonic field. Ultrason Sonochem 2008;15: 995-1000.

12. Jambrak AR, Lelas V, Mason TJ, Krešić G, Badanjak M. Physical properties of ultrasound treated soy proteins. J Food Eng 2009;93:386-93.

13. Ovissipour M, Kenari AA, Motamedzadegan A, Nazari RM. Optimization of enzymatic hydrolysis of visceral waste proteins of yellowfin tuna (Thunnus albacares). Food Bioproc Tech 2012;5:696-705.

14. Kamau SM, Lu RR. The effect of enzymes and hydrolysis conditions on degree of hydrolysis and DPPH radical scavenging activity of whey protein hydrolysates. Curr Res Dairy Sci 2011;3:25-35.

15. Kristinsson HG, Rasco BA. Fish protein hydrolysates: production, biochemical, and functional properties. Cr Rev Food Sci 2000;40; 43-81.

16. Guerard F, Sumaya-Martinez MT, Laroque D, Chabeaud A, Dufossé L. Optimization of free radical scavenging activity by response surface methodology in the hydrolysis of shrimp processing discards. Process Biochem 2007;42:1486-91.

17. Zhu KX, Su CY, Guo XN, Peng W, Zhou HM. Influence of ultrasound 
during wheat gluten hydrolysis on the antioxidant activities of the resulting hydrolysate. Int J Food Sci Technol 2011;46:1053-9.

18. Hsu KC. Purification of antioxidative peptides prepared from enzymatic hydrolysates of tuna dark muscle by-product. Food Chem 2010;122:42-8.

19. Chabeaud A, Dutournié P, Guérard F, Vandanjon L, Bourseau P. Application of response surface methodology to optimise the antioxidant activity of a saithe (Pollachius virens) hydrolysate. Mar Biotechnol 2009;11:445-55.

20. Adler-Nissen J. A review of food protein hydrolysis specific areas: enzymic hydrolysis of food proteins. New York, USA: Elsevier Applied Science Publications; 1986. p. 57-131.

21. Dinis TCP, Madeira VMC, Almeida LM. Action of phenolic derivatives (acetaminophen, salicylate, and 5-aminosalicylate) as inhibitors of membrane lipid peroxidation and as peroxyl radical scavengers. Arch Biochem Biophys 1994;315:161-9.

22. Oyaizu M. Studies on products of browning reaction: antioxidative activity of products of browning reaction prepared from glucosamine. Jpn J Nutr 1986;44:307-15.

23. Shimada K, Fujikawa K, Yahara K, Nakamura T. Antioxidative properties of xanthan on the anti-oxidation of soybean oil in cyclodextrin emulsion. J Agric Food Chem 1992;40:945-8.
24. Aspmo SI, Horn SJ, Eijsink VGH. Enzymatic hydrolysis of Atlantic cod (Gadus morhua L.) viscera. Process Biochem 2005;40:1957-66.

25. You SJ, Wu J. Angiotensin-I converting enzyme inhibitory and antioxidant activities of egg protein hydrolysates produced with gastrointestinal and nongastrointestinal enzymes. J Food Sci 2011;76: C801-C7.

26. Fang X, Xie N, Chen X, Yu H, Chen J. Optimization of antioxidant hydrolysate production from flying squid muscle protein using response surface methodology. Food Bioprod Process 2012;90:676-82.

27. Zhuang YL, Zhao X, Li BF. Optimization of antioxidant activity by response surface methodology in hydrolysates of jellyfish (Rhopilema esculentum) umbrella collagen. J Zhejiang Univ Sci B 2009;10:572-9.

28. Jia J, Ma H, Zhao W, et al. The use of ultrasound for enzymatic preparation of ACE-inhibitory peptides from wheat germ protein. Food Chem 2010;119:336-42.

29. Wu JH, Wang Z, Xu SY. Enzymatic production of bioactive peptides from sericin recovered from silk industry wastewater. Process Biochem 2008;43:480-7.

30. Rajapakse N, Mendis E, Jung WK, Je JY, Kim SK. Purification of a radical scavenging peptide from fermented mussel sauce and its antioxidant properties. Food Res Int 2005;38:175-82. 